\title{
Medio ambiente versus Desarrollo: Experiencias en el Derecho ambiental norteamericano*
}

\author{
Jesús Jordano Fraga \\ Doctor en Derecho \\ Prof. Ayudante de Derecho Administrativo
}

Sumario: I. INTRODUCCIÓN. II. ESPACIOS PROTEGIDOS $V$. DESARROLLO. A) Espacios protegidos $v$. desarrollo. 1) El dogma de la intangibilidad de los Parques Nacionales. Su influencia en nuestro sistema. 2) Algunas alternativas: Dos doctrinas genuinamente americanas utilizables en los conflictos medio ambiente $v$. desarrollo en el entorno de los Parques Nacionales: Nuisance y Public trust doctrine. Otros instrumentos. a) La nuisance doctrine. b) La Public trust doctrine. c) Otros instrumentos. Las fuerzas de mercado al servicio del conflicto medio ambiente $v$. desarrollo. La idea de prevención. B) Wilderness $v$. desarrollo. C) Zonas húmedas $v$. desarrollo. III. LA JURISPRUDENCIA DE LA SUPREM COURT. A) Unión Electric Co. v. Environmental Protection Agency y Tennessee Valley Authority v. HILL: El positivismo ambiental en la Corte Suprema de los Estados Unidos. B) Administración competente para la determinación del interés prevalente en conflicto: California Coast Commission v. Granite Rock Company. El poder regulador de los pueblos indígenas. C) La judicialización de los conflictos desde la National Environmental Policy Act. IV. CONCLUSIONES

\section{INTRODUCCIÓN}

Uno de los temas más candentes del Derecho ambiental es su impacto sobre las actividades económicas. Si el Derecho es la ordenación racional de los intereses en conflicto, la tensión medio ambientedesarrollo es la zona de fricción por excelencia del Derecho ambiental. La relación entre el Derecho ambiental y factores económicos es una de las bases fundamentales para una comprensión adecuada de los problemas y alternativas. La economía ha impactado sobre el Derecho ambiental desde muchas perspectivas operando mutaciones en su estructura más íntima. Sin ánimo de ser exhaustivo este impacto puede cifrarse en los siguientes fenómenos y necesidades: 1) El análisis económico de las consecuencias en términos coste-beneficio de la legislación ambiental ha generado el fenómeno desregulador 1. 2) La realidad

* Estudio realizado en el marco del Proyecto de Investigación PB 93-1190 "Medio Ambiente y Derecho" subvencionado por la DGC y T del Ministerio de Educación y Ciencia.

${ }^{1}$ La desregulación se resume en la máxima de que los controles gubernamentales sólo están justificados cuando resultan necesarios más allá de toda duda y sus beneficios ten- 
económica condiciona la operatividad real del Derecho ambiental en el marco de una asignación de recursos insuficientes convirtiéndolo en un tigre de papel. 3) La necesidad de articulación de los bienes jurídicos en presencia (medio ambiente $v$. desarrollo).

En este estudio vamos a abordar la tercera de las cuestiones. La experiencia del Derecho americano ${ }^{2}$ siempre pionero desde la Environmental Policy Act de 1969 puede ilustrarnos sobre modelos y alternativas posibles en la búsqueda del desarrollo sostenible o la compatibilización del desarrollo con la preservación del medio ambiente.

\section{ESPACIOS PROTEGIDOS VERSUS DESARROLLO}

Paradójicamente Estados Unidos, un país tan dominado por el análisis económico del Derecho o por el todopoderoso mercado, posee una

gan mayor peso que sus costos para la sociedad. Para un análisis del fenómeno desregulador en el Derecho ambiental norteamericano, véase nuestro estudio "La Utilización de los Organismos Autónomos en la Administración Ambiental: Las Agencias de Medio Ambiente», en Administración Instrumental, Libro Homenaje a MANuEl Francisco ClaVero Arévalo, Ed. Civitas, Madrid 1994, pág. 491.

2 En la doctrina ius ambientalista norteamericana han reflexionado especialmente sobre esta problemática: Richard RoBINSON, «Legal problems in the protection of recreational values», University of b. Columbia Law Review, vol. 6, 1971, June n. ${ }^{\circ}$ 1, págs. 237-257; Joseph BocKRATH, «Environment, Development, and the national interest: Problem in definitions and prerogatives", Natural Resources Lawyers, Vol. II, n. ${ }^{\circ} 1,1975$, págs. 29-40; David L. CALliES, "Land Use and Critical Areas: Preservation and Development Compromise in England and Australia», Columbia Journal of Environmental Law, Vol. 5, Primavera, 1979, n. ${ }^{\circ} 2$ págs. 265-282; David J. BRowER, «Management plans for environmentally sensitive areas", Zoning and Planning Law Report, vol. 3, n. ${ }^{\circ}$, marzo 1980,págs. 17-24; Thomas M. RICKART, "Wilderness land preservation: The uneasy reconciliation of multiple and single use land management polices", Boston College Environmental Affairs Law Review, vol. 8, n. ${ }^{\circ} 4,1980$, págs. 873-917; Harold J. CREEL, "Barrier islands: The conflict between federals programs that promote preservation and those that promote development", South Carolina Law Review, vol. 33, 1981, págs. 373-386; Richard O. MCDonalD, "Land use planning in the coastal zone: Protecting a sensitive ecosystem with transferable development credits", Santa Clara Law Review, vol. n. ${ }^{\circ} 21$, 1981, págs. 439-470; Julie Durel LIVAUDAIS, "Conflict interest in Southern Lousiana's Wetlands: private developers versus conservationist and the State and Federal Regulatory Roles", Tulane Law Review, vol. 56, abril 1982, n. ${ }^{\circ}$, págs. 1.006-1.034; Carol D. RASNIC, "The conflict between the environmentalists and the surface mining industry: Federal legislation and litigation", Northem Kentucky Law Review, vol. 9, n. ${ }^{\circ}$ 3, 1982, págs. 427-444; Richard I. GoldSMITH \& William C. BANKS, "Environmental values: Institutional responsibility and the Supreme Court", Harvard Environmental Law Review, vol. 7, 1983, págs. 1-39; Gregory W. EDWARDS, «Keeping wilderness areas wild: Legal tools for management», Virginia Joumal of natural resources Law, vol. 6, n. ${ }^{\circ} 1,1986$, pág. 101-141. 
MEDIO AMBIENTE VERSUS DESARROLLO: EXPERIENCIAS EN EL DERECHO AMBIENTAL NORTEAMERICANO

legislación ambiental donde lo valorativo, al menos en teoría, ha sido situado en la cúspide. La mayoría de las leyes ambientales, dice SAGOFF, «enfatizan las consideraciones éticas sobre las económicas hasta el punto de que éstas persiguen proteger la salud, la seguridad y la calidad ambiental antes que hacer el mercado más eficiente" 3 . Sin duda, un buen botón de muestra de primacía de lo valorativo es la presencia de estándares de protección frente a emisiones contaminantes para la población sensible (esto es, los niveles de permisividad se fijan en atención a los sujetos minoritarios susceptibles de ser afectados, como los enfermos asmáticos o personas alérgicas). La Corte Suprema de los Estados Unidos no siempre ha respaldado el lenguaje ambientalista impreso en las normas pioneras ${ }^{4}$. Así, en Stryckers's Bay Neightborhood Council v. Karlem ${ }^{5}$, Sentencia dictada el 7 de enero de 1980, la Suprem Court ha afirmado que National Environmental Policy Act no «jerarquiza los aspectos ambientales sobre otras consideraciones apropiadas".

\section{A) Espacios protegidos $v$. desarrollo}

1) El dogma de la intangibilidad de los Parques Nacionales. Su influencia en nuestro sistema

También en materia de conservación de la naturaleza la legislación ambiental americana ha ido por delante del resto de los países de nuestra área jurídico-cultural. El Yosemite National Park fue declarado por Ley del Congreso de los Estados Unidos el 30 de junio de 1864. El Parque nacional de Yellowstone, fue declarado por el Congreso en 1872. Lo cierto es que estas primeras declaraciones estuvieron presididas por ideas de apertura al uso recreacional de los recursos naturales.

\footnotetext{
3 SAGoFF, "Where Ickes Went right or Reason and Rationality in Environmental Law", Ecology Law Quarterly, vol. 14, 1987, págs. 272-273.

${ }^{4}$ En este sentido GoldsMrrh \& BANKs han afirmado que "desafortunadamente, la Corte Suprema terminó con esta nueva era poco tiempo después de su inicio... La interpretación por la Corte Suprema de esta legislación refleja su limitada simpatía por los valores ambientales» («Environmental values: Institutional responsability...», cit., pág. 33).

5444 U. S. 223, 227 (1980). Esta Sentencia ha sido calificada por GoldsmrTH \& BANKS como «la decisión más dañina al declarar que el mandato ex NEPA (esto es, la obligación de realizar evaluación de impacto ambiental en caso de Federal Major Action), es esencialmente procedimental» («Environmental values: Institutional responsibility...» cit., pág. 5). En idéntico sentido, Brower («Management Plans for environmentally..., cit., pág. 24).
} 
La concepción americana de espacio protegido posee diferencias fundacionales. La diferente realidad (un país de gran extensión, donde existen zonas vírgenes en las que la civilización no ha dejado su huella) ha determinado diferencias cuantitativas y cualitativas. Frente a lo anecdótico (al menos en lo territorial) de nuestros primigenios parques nacionales, Yellowstone comprendía más de dos millones de acres en los Estados de Wyoming, Montana e Idaho ${ }^{6}$. Hoy existen más de 300 parques nacionales con una extensión superior a muchos países de la comunidad internacional. Pero también existen diferencias cualitativas. Es lo que podríamos denominar el dogma de la intangibilidad. La Ley de creación del Parque Nacional de Yellowstone ordenaba al Secretario de Interior la promulgación de normas y reglamentos que «asegurasen la preservación de todo daño o expoliación, de los bosques, depósitos minerales, curiosidades o bellezas naturales dentro de dicho parque, así como su mantenimiento en sus condiciones naturales» 7. La moderna legislación reguladora del National Park Service promulgada en 1916 y reformada en 1978 dispone que el objetivo de este organismo es:

"conservar los paisajes y los objetos naturales e históricos, así como su vida salvaje" a fin de dejarlos intactos (literalmente, unimpaired) para el disfrute de las futuras generaciones» 8 .

Otra de las figuras de protección, las wilderness son, como veremos, áreas donde no existen testimonios de la presencia humana. No se trata de que una actividad pueda ser ejercida dentro de los espacios adoptando aquella o esta prevención. No se trata de que los efectos de determinadas actividades sean corregidos a posteriori. En la doctrina y en los grupos conservacionistas está presente la idea de que determinadas actividades son incompatibles con la idea de la preservación en su natural condition ${ }^{9}$.

\footnotetext{
${ }^{6}$ Recuérdese que un acre son 40 0 47 áreas.

7 Textualmente esta Ley del 1 de marzo de 1872 ordenaba al Secretario de Interior "to provide for the preservation, from the injury or spoliation, of all timber, mineral deposits, natural curiosities, or wonders within said park, and their retention in their natural condition".
}

$8 \S 1,39$ Stat 535 (1916), codificada como 16 USC. $\S \S 1-20$ G (1982)

${ }^{9}$ Así, EDWARDS, "Mining is incompatible with efforts to keep wilderness areas in their natural condition", «Keeping wilderness areas wild: Legal tools..., cit., págs. 106-107. 
Alguna vez estos planteamientos ultraconservacionistas han recibido respaldo jurisprudencial. En Izaak Walton League v. St. Clair ${ }^{10}$, el Juez Neville de la District Court of Minnesota declaró:

«Si se acepta la premisa de que las actividades mineras y las wilderness son valores opuestos y que son anatemas una respecto de la otra, entonces parecería que promulgando la Wilderness Act el Congreso hizo un ejercicio de futilidad si los Tribunales adoptasen la tesis según la cual los derechos sobre los minerales prevalecen sobre los objetivos preservacionistas de las wilderness". Cualquier uso de la superficie para la exploración o extracción de minerales constituye un uso irrazonable porque la superficie deja de ser indómita. El desarrollo minero, por su propia definición, no puede tener lugar en una wilderness area... En la opinión de este Tribunal los objetivos de preservación de las wilderness desautorizan y anulan las previsiones contrarias sobre derechos mineros de la Ley».

De sobra es conocido que esta filosofía "ultranaturalista» o "hiperconservacionista" ha provocado que las autoridades no apagasen los incendios provocados por un rayo por entender dicha intervención indeseable y contra natura. Intangibilidad. ¿Ha sido ésta la causa de la excelente preservación de los Parques Nacionales americanos? ¿Ha sido transplantada sin más esta filosofía a nuestro sistema? ¿Es la intangibilidad la causa originaria del conflicto medio ambiente-desarrollo en los espacios protegidos?

Preguntas tan complejas no tienen nunca respuestas simples. Para responder a la segunda pregunta formulada es necesario analizar nuestro sistema. La compatibilización de la protección del medio ambiente y el desarrollo afirmada por nuestra jurisprudencia constitucional (así, las STC 4 de noviembre de 1984 y 19 de octubre de 1989) ${ }^{11}$, se combina en el plano legislativo con dos tipos de previsiones de compatibilización y de supremacía. Claramente es una previsión de supremacía valorativa ambiental el art. 9 de la Ley 4/1989, de 27 de marzo: «La utilización del suelo con fines agrícolas, forestales y ganaderos deberá orientarse al mantenimiento del potencial biológico y capacidad productiva del

10353 F. Supp 698 (D. Minn. 1973).

11 Vid. nuestro artículo «La Tensión Medio Ambiente/Desarrollo en la Jurisprudencia del Tribunal Constitucional y del Tribunal Supremon, Revista Andaluza de Administración Pública, n. ${ }^{\circ}$ 17, enero-febrero-marzo, 1994, págs. 87-99. 
mismo, con respeto a los ecosistemas del entorno". Incluso en las previsiones de compatibilización están presentes notas de supremacía. Esta es la idea presente en los artículos $13.2 .^{\circ}$ y $14.2 .^{\circ}$ de la Ley $4 / 1989$. Así, en los Parques «se podrá limitar el aprovechamiento de los recursos naturales, prohibiéndose en todo caso los incompatibles con las finalidades que hayan justificado su creación». En las Reservas «estará limitada la explotación de recursos, salvo en aquellos casos en que esta explotación sea compatible con la conservación de los valores que se pretenden proteger».

La tercera pregunta que se ha formulado es en realidad una insinuación. En la mente de todos está el recuerdo de una actuación violenta indefendible en un Estado de Derecho: La ocupación en 1992 por la fuerza de los ganaderos de Almonte de determinadas tierras para su aprovechamiento como pastos. También es probable que estén en la mente de todos las afirmaciones (como poco exageradas) de los responsables del Parque Nacional de Doñana afirmando que los «daños ecológicos» generados por burros, caballos, mulas y vacas eran «irreversibles». Los ejemplos son innumerables. Las limitaciones pueden llegar a convertir a los espacios en celdas de cristal aisladas del ser humano (así lo ha denunciado GARCÍA DE ENTERRÍA, en reciente tercera página del Diario $\mathrm{ABC}$, calificando como absurdas tales limitaciones respecto del Plan de Ordenación de los Recursos Naturales de Picos de Europa). No parece descabellado pensar que prohibiciones absurdas basadas en dogmas sin fundamento generen en el futuro similares reacciones poniendo en peligro real los valores que se intentan superproteger. El desarrollo sostenible puede ser esa idea de síntesis superadora de concepciones abocadas al fracaso social.

2) Algunas alternativas: Dos doctrinas genuinamente americanas utilizables en los conflictos medio ambiente $v$. desarrollo en el entorno de los Parques Nacionales: Nuisance y Public Trust doctrine. Otros instrumentos

Desde un punto de vista estructural, el factor determinante y más significativo del ordenamiento jurídico estadounidense es la existencia de un marco federal. En el conflicto medio ambiente/desarrollo existe desde una perspectiva decisional una cuestión competencial de suprema importancia. ¿A quién corresponde el poder de determinación del interés predominante? ¿Hasta dónde llega el margen de decisión de los Estados (ya sea a favor o en contra de un proyecto que afecta a sus intereses económicos o ambientales)? En el fondo subyace 
un conflicto de intereses. BocKRATH ha propuesto la solución desde el concepto de medio ambiente: "Este debe ser definido como el conjunto de todas las condiciones humanas de vida, incluyendo las naturales, económicas y sociales, y debe ser visto en una escala nacional antes que provincial 12 .

El Congreso de los Estados Unidos cada vez que ha procedido a declarar un determinado espacio como Parque Nacional se ha asegurado previamente de incluir la suficiente cantidad de tierras como para rodear y proteger el punto neurálgico de dichos parques. Cuando esa zona neurálgica ha sido amenazada por una actividad exterior 13 , el remedio más simple y efectivo ha sido la adquisición gubernamental de las tierras circundantes ${ }^{14}$. Es la Buffer protection (protección por amortiguación), "estrategia simple e inadecuada a largo plazo" puesto que

12 «Environment, Development and the National...», cit., pág. 39-40.

13 Históricamente las amenazas que han existido en la realidad americana parecen sin duda más serias. SHEPARD da cuenta, por ejemplo, de los daños provocados por una compañía maderera en los límites del Redwood National Park de California, y la construcción de una central nuclear cerca del Indiana Dunes National Lakeshore. Las mayores amenazas provienen de la existencia de propiedades privadas en los límites de los Parques Nacionales ("The scope of Congress'constitutional power under the property clause: Regulating non-federal property to further the purposes of national parks and wilderness areas, Boston College Environmental Affairs Law Review, vol. 11, 1984, pág. 480).

14 En nuestro ordenamiento el mecanismo de protección frente a estas agresiones viene determinado por el art. 18.1 de la Ley 4/1989: «En los Espacios Naturales Protegidos declarados por Ley se podrán establecer Zonas Periféricas de Protección destinadas a evitar impactos ecológicos o paisajísticos procedentes del exterior. Cuando proceda, en propia Ley de creación, se establecerán las limitaciones necesarias.» Sin duda, la contrapartida de tan potencial pesada carga es el apartado $2 .^{\circ}$ de este mismo artículo que establece que «con el fin de contribuir al mantenimiento de los espacios naturales protegidos y compensar socio-económicamente a las poblaciones afectadas, en sus disposiciones reguladoras podrán establecerse Áreas de Influencia Socioeconómica, con especificación del régimen económico y compensación adecuada al tipo de limitaciones. Estas Áreas estarán integradas por el conjunto de los términos municipales donde se encuentre el espacio natural de que se trate y su Zona Periférica de Protección». Con anterioridad a este precepto había sido promulgado el RD 1.105/1982, de 14 de mayo (BOE de 1 de junio) dirigido a regular las normas sobre actuación del ICONA en las zonas de influencia socioeconómica de los Parques Nacionales. Desde 1982 a 1988, según MEstre MORALES-AlBo y ZAMORA VICENTE, se ha destinado a este fin, con evidente discontinuidad temporal, la irrisoria cantidad de 1.445 millones de pesetas. Así, por ejemplo, en el último año de esta estadística se gastaron 120 millones para el total de los espacios y un total de 54 municipios (Análisis y resultados del RD 1.105/1982 en Los Parques Nacionales. Aspectos Jurídicos y Administrativos, Publicaciones del Ministerio de Agricultura, Pesca y Alimentación, ICONA, Madrid, 1988, págs. 70-71). 
«las tierras vírgenes adyacentes a los Parques son cada vez más escasas y prohibitivamente caras" y "teóricamente sin límites» 15.

En cuanto al modo de adquisición, en el Derecho norteamericano caben diversas posibilidades. Cuando se trata de adquisición de terrenos con fines de protección ambiental se recurre a tres tipos básicos 16 : 1) Fee simple o less than fee ${ }^{17}$, aunque quepan adquisiciones subordinando las futuras a determinados usos que caso de ser incumplidos provocarán la reversión de la propiedad a la Administración titular originaria. 2) Easements (servidumbres) ${ }^{18}$. Se adquiere el derecho a usar la propiedad de otro sólo para determinados propósitos. El Estado de Wisconsin, por ejemplo, ha desarrollado un amplio programa de adquisición de servidumbres de vistas (scenic easements).

La efectividad de esta política de adquisiciones ha sido limitada dados los escasos fondos previstos. De otro lado, los procedimientos de adquisición forzosa dejan mucho que desear en cuanto a su agilidad (es necesaria la obtención de un permiso emitido por un Comité del Congreso) y efectividad (pues genera el efecto perverso de fomentar las actividades que pretende evitar al incentivar un desarrollo que forzará la existencia de la necesidad de adquisición) ${ }^{19}$. Por eso, normalmente los intentos de eliminar actividades potencialmente dañosas para los fines de protección ambiental en las proximidades de los espacios protegidos a veces se han limitado a la promoción de acuerdos con las autoridades locales a quo, a fin de obtener la aprobación de un planeamiento urbano estricto en cuanto a sus estándares proteccionistas (Protective Zone Legislation) 20.

15 «Protecting National Parks from developments beyond their borders». University of Pennsylvania Law Review, vol. 132, 1984, págs. 1.190-1191. En el mismo sentido, CoHEN, «The National Landmark Program: A Natural Areas Protection Technique for the 1980s and Beyond», UCLA Joumal of Environmental Law \& Policy, vol. 3, 1982, pág. 120.

16 Vid. BowDEN, "Protecting Our Environment Through Legislation: Approaching a New Concept of Property", Real Estate Law Joumal, vol. 4, 1975, págs. 171-172.

${ }^{17}$ Esta palabra derivada de feudal o feodor, significa pleno dominio o propiedad susceptible de ser vendida o heredada, o bienes raíces de pleno dominio. Fee simple es el dominio pleno, absoluto e inmediato (fee simple absolute in possesion). (ALCARAZ VARo \& HugHES, Diccionario de Términos Jurídicos, Inglés-español, Español-inglés, Ariel Barcelona, 1992, voz fee, pág. 139).

18 Alcaraz Varo \& Hughes, Diccionario de Términos Jurídicos..., cit., voz easement, pág. 118.

19 Vid. SHEPARD, «The scope of Congress' constitutional power under...», cit., págs. 516-517.

20 SHEPARD, op. ult. et loc. cit. Sin embargo, BRower, por el contrario, cree que «un cuidadoso estudio puede demostrar que el ahorro y otros beneficios de los programas de 
En el epígrafe hemos adelantado la existencia de dos doctrinas genuinamente americanas, del Common Law, utilizables en los conflictos medio ambiente-desarrollo en el entorno de los Parques Nacionales: La nuisance y la Public trust doctrine.

\section{a) La nuisance doctrine}

La nuisance podría decirse que es el equivalente en Derecho anglosajón a nuestras relaciones de vecindad. Existen la public nuisance y la private nuisance. Según RODGERS nuisance «es una palabra derivada de la palabra francesa perjuicio. Una public nuisance puede ser definida como una irrazonable interferencia respecto de un derecho común a la ciudadanía general. Un private nuisance es una sustancial e irrazonable interferencia respecto del uso y disfrute de la tierra» ${ }^{21}$. Esta definición legal es ampliada por la Restatement, Second, Torts § $821 \mathrm{D}(2)$ en el sentido de establecer qué circunstancias pueden sostener una declaración de irrazonabilidad. Estas son las siguientes: A) Si la conducta implica una sustancial interferencia respecto de la salud pública, la seguridad pública, la paz pública, la comodidad pública o la conveniencia pública»; B) Si la conducta está prohibida por una ley, ordenanza o regulación administrativa; y por último, C) Si la conducta es de naturaleza continua o ha producido un efecto permanente o perdurable a largo plazo, y desde el actual estado de conocimiento posee un efecto nocivo sobre el Derecho público.

TARLOCK ha propuesto la aplicación de esta doctrina como solución al problema de la interferencia del desarrollo más allá de los límites de los Parques Nacionales. Si se considera al Gobierno como un ser análogo a un propietario privado de la tierra o si se considera que el uso de los parques es un derecho común perteneciente a la colectividad, la nuisance doctrine sería ideal como instrumento que inviste de autoridad al gobierno para demandar en favor del control de las actividades potencialmente dañosas de los propietarios adyacentes a los Parques Nacionales 22.

adquisición pública a fin de administrar el desarrollo, puede ser mucho mayor que su coste». De otro lado, «a veces no es necesaria la adquisición de grandes extensiones de tierra para reducir un desarrollo indeseado: la adquisición de un área ecológicamente sensible estratégicamente situada en la línea previsible de una zona vocacionalmente destinada a un desarrollo intensivo puede hacer bajar la densidad residencial en torno a ella ( "Management Plans for environmentally...", cit., pág. 20).

21 Environmental Law, West Publishing Co. St. Paul, Minnesota, 1977, pág. 102.

22 "For Whom the National Parks?», recensión crítica al libro de SAX, Mountains without handrails: Reflections on the National Parks, en Standford Law Review, n. ${ }^{\circ}$ 34, págs. 255. 
La jurisprudencia ha aplicado la nuisance doctrina en varios casos: Camfield v. United States ${ }^{23}$ y United States v. Atlantic-Richfield Co. ${ }^{24}$.

1. En Camfield v. United States los demandados habían erigido una cerca apropiándose de $\mathbf{2 0 . 0 0}$ acres de tierras federales vulnerando una ley federal (la Unlawful Enclosures Act, de 25 de febrero de 1885). La Corte Suprema consideró que la construcción de la cerca constituía una nuisance y mantuvo la constitucionalidad de la legislación federal en cuestión, a pesar de que ésta afectaba a actividades ejercidas en tierras privadas 25 .

2. En United States v. Atlantic-Richfield Co., el Gobierno Federal demandó a una fábrica de aluminio, a fin de obtener una orden judicial que impusiese una reducción de sus emisiones de fluoruro. El Gobierno Federal alegaba que dichas emisiones estaban dañando los bosques y la vida salvaje de Montana's Flathead National Forest y Glacier National Park. La Corte Federal del Distrito de Montana al rechazar las pretensiones de los demandados afirmó que el Derecho federal regulador de la nuisance no había sido derogado por la Clean Air Act.

\section{b) La Public trus doctrine}

La Public trust doctrine se resume en las máximas que afirman que el Gobierno Federal de los Estados Unidos administra las tierras federales como fideicomisario del pueblo de los Estados Unidos y que la autoridad del Congreso para proteger $u$ ordenar dichas tierras no es judicialmente controlable ${ }^{26}$. La utilización de esta doctrina en la preservación de los Parques Nacionales partió de una propuesta doctrinal del Prof. SAX 27. La jurisprudencia ha admitido expresamente la utilización de esta construcción jurídica para fines conservacionistas.

23167 US 518 (1987).

24478 F. Supp. 1.215 (D. Mont. 1979).

25 Para un análisis amplio de esta Sentencia véase SHEPARD, "The scope of Congress' constitutional power under the property...», cit., págs. 494-497.

26 "The Federal Government maintains the public lands in trust for the people of the United States and the congressional authority to protect or dispose of these lands is judicially unreviewable».

27 "The public trust doctrine in natural resources Law", Michigan Law Review, n. 68 , 1970, págs. 471-498. 
MEDIO AMBIENTE VERSUS DESARROLLO: EXPERIENCIAS EN EL DERECHO AMBIENTAL NORTEAMERICANO

Sin embargo, "Mientras que los Tribunales han sido algo proclives para reconocer al Gobierno Federal como fideicomisario de las tierras públicas, éstos han sido menos proclives para establecer que dicha condición impone deberes positivos sobre los oficiales federales. Esta reticencia judicial ha limitado la efectividad de la public trust doctrine como herramienta para combatir las amenazas externas hacia los Parques Nacionales» 28.

En Sierra Club v. Department of the Interior 29 , la asociación ambientalista Sierra Club alegó que el Secretario del Interior estaba desatendiendo la protección del Redwood National Park en California, incumpliendo sus deberes como fideicomisario público (Public trustee) del Parque Nacional. La amenaza combatida por la asociación ambientalista procedía de las actividades de compañías madereras privadas que eran titulares de la mayoría de las propiedades en los terrenos circundantes al Parque Nacional. La explotación extensiva estaba creando problemas de drenaje y erosión dentro del Parque. El Tribunal (en este caso, la United States District Court for the Northern District of California), afirmó que tanto la National Park Service Organic Act como la Redwood National Park Act, imponían deberes positivos al Secretario del Interior para actuar como fideicomisario de los Parque Nacionales. En una decisión posterior (Sierra Club v. Department of the Interior, $398 \mathrm{~F}$. Supp 284, N. D. Cal. 1975), epílogo de la que venimos narrando, el Tribunal declaró que el Secretario del Interior irrazonablemente, arbitrariamente y abusando de su discrecionalidad no había cumplido los deberes impuestos por las leyes antes citadas ${ }^{30}$. La jurisprudencia posterior ha mitigado el alcance de la public trust doctrine como instrumento en la lucha por la preservación del medio ambiente. En Sierra $C l u b v$. Andrus ${ }^{31}$ se llegó a una conclusión contraria, afirmando que la National Park Service Organic Act no imponía «especiales deberes como fideicomisario al Secretario del Interior. Sierra Club (una importante

28 «Protecting National Parks from developments...», cit., pág. 1.197.

29376 F. Supp. 60 (Northern District of California, 1970).

30 Como consecuencia de esta última decisión el Secretario del Interior emprendió las siguientes acciones: 1) Dirigió una petición a la Office of Management and Budget solicitando fondos para la adquisición de propiedades en los límites del Parque Nacional. 2) Solicitó autoridad normativa para regular las actividades de las compañías privadas en los límites del Parque Nacional. 3) Solicitó al Estado de California la adopción de medidas legales; y 4) solicitó al Departamento de Justicia que demandase a las citadas compañías madereras («Protecting National Parks from developments...», cit., pág. 1.199).

31487 F. Supp. 443 (DDC, 1980). 
asociación ecologista) impugnaba la decisión del Secretario del Interior de no interferir la construcción de proyectos de desarrollo energético en el norte de Arizona y en el sur de Utah que supuestamente podían afectar las aguas que atravesaban el Grand Canyon National Park y otras tierras públicas. Y es que, como se ha afirmado, la principal desventaja de la public trust doctrine como instrumento es «que su aplicación depende de la interpretación judicial de los conceptos jurídicos indeterminados empleados por las leyes (upon... the vague statutory language). A causa de esta imprecisión legal, los Tribunales poseen libertad para afirmar la existencia de deberes positivos» 32 .

c) Otros instrumentos. Las fuerzas de mercado al servicio del conflicto medio ambiente v. desarrollo. La idea de prevención

$\mathrm{Al}$ margen del furor desregulador es elogiable la existencia de instrumentos efectivos que ponen las fuerzas del mercado al servicio de la protección del medio ambiente. En este sentido, la California Coastal Act de 1976 procedió a la utilización de los transferable developments credits como técnica de protección de ecosistemas sensibles. La California Coastal Zone Act de 1972 había sometido los proyectos de desarrollo a la obtención de un permiso de la Califormia Coastal Zone Conservation Commission. Esta norma estableció como requisito para que el desarrollo fuese autorizado «La ausencia de efectos ecológicos o ambientales adversos", trasladando la carga de la prueba al promotor. La California Coastal Act de 1976 abandonó el lenguaje preservacionista de su antecesora enfatizando, por el contrario, la «utilización equilibrada de los recursos de la zona costera teniendo en cuenta las necesidades económicas y sociales de la población" 33 . En ejecución de la Ley fueron aprobadas el 21 de junio de 1979 las Interpretative Guidelines por la South Coast Regional Commission. Las Interpretative Guidelines establecieron como mecanismo de implementación un programa de Transferable Development Credits. Este mecanismo tenía como objetivo la compensación de los propietarios de parcelas calificadas como inadecuadas para la inmediata construcción (unsuitable for immediate construction), permitiéndoles la enajenación del desarrollo potencial de sus propiedades a constructores con proyectos en áreas de desarrollo. Adquiriendo los Transferable Development Credits, los constructores obtienen a cam-

32 «Protecting National Parks from developments...», cit., pág. 1.200.

33 MC Donald, «Land use planning in the coastal zone: Protecting a sensitive ecosystem...n, cit., págs. 444-445. 
bio la autorización de intensificación de uso de sus propiedades más allá de las limitaciones vigentes en el planeamiento (zoning) ${ }^{34}$. El sistema se completa mediante la designación de donor areas y potential reciver sites, esto es, aquellas zonas del territorio en las que se crean los derechos de desarrollo transferibles y las zonas en las que mediante su adquisición será posible incrementar las posibilidades de desarrollo urbanístico ${ }^{35}$. Desde la doctrina se han apuntado cuáles debieran ser las líneas medulares para lograr el éxito y efectividad de los programas de derechos transferibles. TRIPP \& DUDEK, inspirándose en programas que han tenido éxito en la realidad (el programa de New Jersey Pinelands) estiman que éstas deben ser las siguientes:

1. La Administración debe poseer de forma clara y expresa autoridad legal para generar derechos transferibles y ejecutar el programa.

2. La Administración responsable del programa debe poseer capacidad técnica para diseñạr e implementar el programa.

3. La Administración responsable debe poseer un control exclusivo sobre el recurso, y el uso de los derechos transferibles debe ser el único modo de incrementar la densidad en las áreas de crecimiento.

4. El programa debe poseer objetivos claros y específicos.

5. Los programas de derechos transferibles funcionan mejor cuando se aplican a problemas de relevancia regional.

6. El problema de asignación de recursos debe ser definido de forma que los derechos transferibles tengan valor económico y que existan incentivos para comprarlos y venderlos.

7. La asignación de los derechos transferibles debe basarse en fórmulas simples y equitativas (por ejemplo, un número de derechos por acre).

\footnotetext{
34 Mc Donald, op. cit., pág. 450.

35 Según Mc DONALD, en 1981 desde la puesta en marcha del programa habían sido objeto de comercio 20 Transferable Developments Credits a un precio de 35.000 a 40.000 dólares. Estos procedían de las donor areas más inadecuadas para el desarrollo presente. Como la cantidad de donors areas disminuye, los Transferable Developments Credits habrán de ser generados desde parcelas progresivamente más atractivas para el inmediato desarrollo. Esto puede influir en el incremento del precio de los Transferable Developments Credits (op. cit., pág. 467).
} 
8. Para asegurar su valor económico, su compra y venta debe implicar costes transaccionales mínimos (por ejemplo, ayudando a la identificación de los operadores del mercado, generando una absoluta transparencia) 36 .

Otra técnica digna de reflejarse aquí es el National Landmark Program establecido en 1962 mediante una executive order del Secretario del Interior, a pesar de no haber sido expresamente autorizado por ninguna Ley. El objetivo de este programa es identificar y promover la preservación de ejemplos representativos de todos los mayores tipos de ecosistemas y formaciones geológicas de los Estados Unidos, siendo el único programa federal que sistemáticamente ha inventariado el territorio nacional. El funcionamiento de este programa según CoHEN es el siguiente: 1) Como base científica orientadora de criterio de selección se realizan una serie de estudios regionales realizados por científicos de reconocido prestigio bajo contrato con el Park Service; 2) Cada área potencial recomendada por los estudios previos es evaluada in situ por científicos de la Universidad local en orden a clarificar si la zona se encuentra dentro de los estándares de "nacional relevancia» (national significance); 3) Esta evaluación es revisada dentro del Park Service por un equipo de tres científicos, reclutados también en la comunidad académica; 4) Si esta última revisión es aprobada se remite al Secretario del Interior para su aprobación. En esta fase la zona es declarada como National Natural Landmark; 5) En la última fase, los miembros del Programa contactan con el propietario, público o privado, informándole de la designación y requiriéndole a los efectos de la formulación de un acuerdo denominado owner agreement, mediante el cual éste se compromete a la gestión de la zona de forma compatible con la conservación de los valores a proteger. Si el propietario firma el acuerdo recibe un certificado y placa del Park Service en reconocimiento de su participación voluntaria en el National Landmark Program ${ }^{37}$. Creo que son destacables varios aspectos. En primer lugar, la concepción dinámica del programa. No se trata de un inventario meramente estático. Se consagra una acción administrativa permanente de protección de los valores ambientales presuntos. En segundo lugar, la filosofía de colaboración que impregna el owner agreement. Como dice CoHEN, «el National Landmark Program tan sólo pretende informar a los propietarios de su con-

36 «Institutional Guidelines for Designing Successful Transferable Rights Programs», Yale Joumal on Regulation, vol. 6, 1989, págs. 375-377.

37 COHEN, «The National Landmark Program: A Natural Areas Protection Technique for the 1980s and Beyond». UCLA Joumal of Environmental Law \& Policy, vol. 3, 1982, págs. 121, y 122 a 125 . 
trol respecto de una zona natural de gran valor, y persuadirlos para que gestionen su propiedad de forma que no se lesione ésta", un logro nada desdeñable «dado su modesto presupuesto y staff» 38.

Otros instrumentos utilizados son los económico-fiscales. Estos van desde la concesión de ayudas financieras para los propietarios de terrenos donde el desarrollo es severamente limitado o prohibido, las ayudas e incentivos para que algunos propietarios continúen cultivando sus tierras, hasta el establecimiento de ventajas fiscales con finalidad disuasiva que se pierden si se lleva a cabo el desarrollo ${ }^{39}$. A menudo, la utilización de técnicas económico-fiscales se instrumenta a través de un contrato. El propietario se compromete a restringir el uso de su tierra como open public space a cambio de una promesa de la Administración de gravar fiscalmente la tierra de acuerdo con su valor productivo (fiscalmente ventajoso para el propietario). El contrato sólo puede ser resuelto, exigiendo la devolución de la deuda cuando el valor de los terrenos sea desproporcional a las ventajas fiscales obtenidas ${ }^{40}$.

Estas fórmulas y otras se han desarrollado en el Derecho Ambiental de los diferentes Estados. En la legislación de California se ha diseñado la posibilidad de acuerdos voluntarios entre propietarios y el Departamento de Caza y Pesca en el marco de los natural community conservation plans dirigidos a la preservación de la biodiversidad compatibilizada con el desarrollo ${ }^{41}$.

\section{B) Wilderness $v$. desarrollo}

La existencia de grandes extensiones de territorio "vírgenes» impulsó desde siempre actuaciones dirigidas a la preservación de dichas áreas. En 1961 el Congreso de los Estados Unidos promulgó la Wilderness Act ${ }^{42}$. A pesar de ello hay quien ve precisamente en esta legislación la mayor amenaza para las Wilderness 43 .

\footnotetext{
38 "The National Landmark Program: A Natural Areas Protection...», cit., págs. 126 y 154.

39 BROWER, «Management Plans for environmentally...», cit., pág. 23.

40 BowDEN, «Protecting Our Environment Through Legislation...», cit., pág. 170-171.

41 California Fish \& Game Code $\S \S 2.805,2.810$ (West Supp. 1993).

42 National Wilderness Preservation Sistem Act, 16 USC $\S \S 1.131-1.136$.
} 
El objetivo declarado de esta Ley era asegurar «que el incremento de población, acompañado de la expansión de asentamientos y del crecimiento de la mecanización, no ocupe y modifique todas las zonas dentro de los Estados Unidos, no dejando tierras destinadas a la preservación y protección de sus condiciones naturales" ${ }^{44}$. Las Wilderness son definidas, por la citada Ley, como aquellas tierras federales en una "condición primigenia" y "no desarrollada" sin permanentes "mejoras o instalaciones hechas por el hombre», de una extensión de al menos 5.000 acres o con amplitud suficiente que permita su preservación y uso de forma intangible pudiendo contener valores ecológicos, geológicos, científicos, educacionales, paisajísticos o históricos 45 . La decisión de si una determinada zona debe ser conservada en tanto Wilderness pertenece al Congreso de los Estados Unidos, pero el proceso se inicia a instancias de determinadas Agencias administrativas dependientes del Departamento del Interior ${ }^{46}$. Lo cierto es que, al amparo de la definición legal de su figura, su uso ha sido restringido. El Forest Service, interpretando restrictivamente la definición de la Wilderness Act, sólo ha considerado como tales «las áreas más naturales adecuadas para la preservación", excluyendo otras en las que exista la presencia de un desarrollo menor (la existencia de caminos rurales). Ello ha provocado que el proceso de designación haya limitado severamente la expansión de la figura 47. La Wilderness Act permite usos económicos en el interior de las zonas protegidas. Estos usos permitidos son, como hemos visto, la actividad minera, los usos recreacionales y los pastos: Estas actividades se hallan sujetas a determinadas prevenciones (en Wilderness Act y en los reglamentos de las diferentes Agencias con competencia, como el

43 EDWARDS cree "irónicamente que dos de las mayores amenazas hacia las wilderness areas derivan de la misma Wilderness Act: La Ley crea una difícil alianza entre la administración y protección de las áreas incluidas en el sistema. Aunque los usos no compatibles con el objetivo de la Ley son generalmente prohibidos, dicha norma permite algunos usos incompatibles (actividades mineras y usos recreacionales)", "Keeping wilderness areas wild: Legal tools...», cit., pág. 110.

4416 USC $\S 1.131$ (a).

45 Textualmente: «an area of undeveloped Federal Land retaining its primeval character and influence, without permanent improvement or human habitation, which is protected and managed so as preserve its natural conditions and which generally appears to have been affected primarily by the forces of nature, with the imprint of man'works substantially unnoticeable». 16 USC $§ 1.131$ (a).

46 Para un análisis del sistema de designación y sus problemas, véase RICKART, «Wilderness Land Preservation...», cit., págs. 886 y ss.

47 RICKART, «Wilderness Land Preservation...», cit., pág. 892. 
MEDIO AMBIENTE VERSUS DESARROLLO: EXPERIENCIAS EN EL. DERECHO AMBIENTAL NORTEAMERICANO

Forest Service): así, existe el principio de la utilización exclusiva de la superficie para los fines para los que fue concedida (si se autoriza la ocupación para desarrollar una actividad minera no cabe construir un chalet o infraestructuras no necesarias para la explotación minera); la posibilidad de suspender o anular los permisos concedidos; el principio del desarrollo de la actividad en concordancia con el mantenimiento de las Wilderness, etc...

Según EdWARDs, las amenazas más frecuentes para las Wilderness provienen de: 1) La permisividad de usos incompatibles con la preservación (actividad minera, usos recreacionales y pastos). 2) Las amenazas provenientes de más allá de sus fronteras. 3) Las prácticas de administración inapropiadas ${ }^{48}$. En su opinión la solución a estos problemas estriba en las siguientes medidas: 1) Aplicación de las posibilidades existentes en el ordenamiento, incluyendo la Evaluación de Impacto Ambiental. EDWARDS no descarta la posibilidad de una prohibición legal de las actividades mineras, decisión que sólo estaría en manos del Congreso después de un gran debate público ${ }^{49}$. 2) Cooperación entre las Administraciones públicas a través de acuerdos entre las diferentes Administraciones en los niveles implicados (federal y estatal) 50 .

\section{C) Zonas húmedas v. desarrollo}

La protección de las zonas húmedas (Wetlands), no podría ser de otro modo, se enfrenta a las mismas amenazas Daimielizantes: Desecación, drenaje, diques, canalizaciones, riegos abusivos, alteración de los ciclos hidrológicos. El régimen jurídico de su protección descansa en normas federales potencialmente aplicables en la Coastal Management Act, Endangered Species Act, Federal Pollution Control Act, National Environmental Policy Act.

\footnotetext{
48 «Keeping wilderness areas wild: Legal tools...», cit., págs. 109-110.

49 "Keeping wilderness areas wild: Legal tools...», cit., pág. 116.
}

50 «Keeping wilderness areas wild: Legal tools...», cit., pág. 132. Las ventajas de la cooperación derivan: 1) de la necesidad de negociación; 2) la adaptación del proceso a las prioridades de cada caso; y 3) la promoción de buenas relaciones que el proceso cooperador implica. La práctica, desde luego, ha demostrado que de la descoordinación de la actuación de las Administraciones públicas pueden nacer programas de desarrollo que choquen de plano con programas preservacionistas. La legislación, como ha dicho CREEL, debe procurar los mecanismos para mejorar la coordinación administrativa ("Barrier islands: The conflicts between federals programs that promote preservations...», cit., pág. 386). 
En la regulación de las Wetlands a cargo de United States Army Corps of Engineers está presente la idea de su importancia: «cualquier destrucción o alteración innecesaria de las zonas húmedas deberá ser rechazada en cuanto contraria al interés público» 51 . Es más: «Ningún permiso deberá ser concedido a menos que los beneficios de la alteración propuesta sobrepasen al daño provocado a las zonas húmedas y que dicha alteración sea necesaria para la obtención de dichos beneficios" 52 .

Esta regulación es producto de una de las victorias en la lucha por su preservación. El objetivo conseguido ha sido la extensión de las previsiones generales de la Federal Pollution Control Act hacia las Wetlands. En Natural resources Defense Council, Inc v. Callaway 53, el Tribunal ordenó al United States Army Corps of Engineers la modificación de su regulación a fin de obtener la extensión de su jurisdicción territorial bajo la sección 404 de la Federal Pollution Control Act 54, para incluir todas las aguas de los Estados Unidos que el Gobierno Federal pudiera constitucionalmente regular bajo la cláusula de comercio con independencia del tradicional concepto de navegabilidad 55. En United States v. Riverside Bayview Homes, Inc. 56, la Corte Suprema declaró que el United States Army Corps of Engineers había actuado razonablemente al interpretar que la Clean Water Act autoriza al citado órgano a exigir permisos para la descarga de materiales en las zonas húmedas adyacentes a otros cursos de agua de los Estados Unidos 57 .

\footnotetext{
5133 CFR. § 320.4 (b)(1) 1980.

5233 CFR. § 320.4 (b)(4) 1980.

53 F. Supp. 685 (DDC 1975).
}

\begin{abstract}
54 Este precepto regula la necesidad de autorización de todas aquellas actividades que supongan la descarga de vertidos en las aguas navegables de los Estados Unidos.

55 LivaudaIs considera que la Sentencia Callaway fue "un espaldarazo para la protección de las zonas húmedas porque desde entonces el permiso exigible bajo la sección 404 de la Federal Water Pollution Control Act es requerido para los vertidos en aguas que no posean un nexus con la navegación" ("Conflict interest in Southern Louisiana's Wetland...», cit., págs. 1.012-1.013).
\end{abstract}

56474 U. S. 121; 106 S Ct. 455 (1985).

57 At. $460-461$. 
MEDIO AMBIENTE VERSUS DESARROLLO: EXPERIENCIAS EN EL DERECHO AMBIENTAL NORTEAMERICANO

Otro importante pronunciamiento jurisprudencial respecto de las Wetlands ha sido Zabel v. Tabb ${ }^{58}$, en el cual la Corte del Quinto Circuito declaró que el United States Army Corps of Engineers debía tener en cuenta el efecto que un proyecto de draga o desecación pudiera tener sobre la conservación, antes de conceder un permiso bajo la sección 404 de la Federal Water Pollution Control Act, incluso si dicho proyecto no estuviese relacionado con la navegación, el control de riadas, o la producción de energía, porque tales proyectos «tienden a destruir el equilibrio ecológico y, por tanto, afectan a la cláusula de comercio sustancialmente» 59. La Corte Federal de Apelación procedió a la revocación de la Sentencia dictada por la Corte de Distrito que afirmaba la falta de autoridad del United States Army Corps of Engineers para denegar permisos por otra razón que fuera la interferencia con las aguas navegables 60 . Estas decisiones han abierto el camino a una jurisprudencia de carácter proteccionista que, por ejemplo, ha ordenado la restauración del dragado de canales sin autorización en los Cayos de Florida por propietarios de terrenos adyacentes (United States v. Sexton States, Inc. 61) o ha estimado en Creppel v. United States Army Corps of Engineers 62 conforme a Derecho la modificación de criterio respecto de la autorización concedida por el United States Army Corps of Engineers al proyecto Harvey Canal-Bayou Barataria Flood control, que dos años después de la autorización inicial, consideró que parte de la zona húmeda afectada por el proyecto citado representaba una zona valiosa, ordenando el uso de compuertas en lugar de una estación de bombeo. Igualmente son de resaltar la serie de pronunciamientos Deltona Corporation v. Alexander 63. En ellos se examinaba la legalidad de la denegación de permisos a una empresa del Estado de Delaware que proyectaba la construcción de una urbanización con canales en Marco Island (Florida). Los criterios

58430 F. 2 d 199 (5th Cir. 1970).

59 Vid. LivaudaIs, "Conflict interest in Southern Louisiana's Wetlands...», cit., págs. 1.013-1.014.

60296 F. Supp. 764 (Middle District of Florida, 1974).

61389 F. Supp. 602 (SD Fla 1974), revisada en parte por la decisión del Quinto Circuito de 1976, 526 F. 2d. 1.293.

62500 F. Supp. 1.108 (ED La, United States District Court for the Eastern District of Louisiana).

63504 F. Supp. 1.280 (United States District Court for Middle District of Florida 1981) y 18 ER C 1.009 (11 th Cir 1982). 
de concesión de permisos se habían endurecido. Para conseguir los estatales Deltona Co. transfirió la propiedad de 4.000 acres al Estado de Florida para destinarlos a propósitos preservacionistas. En 1973 la citada empresa solicitó los permisos federales necesarios, competencia del United States Army Corps of Engineers, que fueron denegados para zonas del proyecto por cuanto destruirían 2.152 acres de zonas húmedas (manglares) y 735 acres del fondo de la bahía de Big Key (Cayo Grande) y Barfield Bay y eran contrarias a la política de conservación de las Wetlands reflejada en la regulación del citado organismo. Sólo fue otorgado un permiso respecto de Collier Bay debido a lo avanzado de los trabajos y a las pérdidas económicas que conllevaría su denegación. Recurrida esta denegación, los Tribunales dieron la razón a la Administración. La base de estas decisiones judiciales fue la aplicabilidad de normas ambientales en el momento, y la negación de que la actuación administrativa fuese arbitraria, caprichosa o con abuso de discrecionalidad.

LIVAUDAIS, autor que ha estudiado con profundidad el problema, considera dos factores como elementos indispensables en la lucha por la preservación de las wetlands: "la construcción armoniosa de los programas federales y estatales como componentes de un único proceso" y el control de la Administración a través de una participación administrativa y jurisdiccional (esta última mediante la citizen suits o acciones ciudadanas en la Clean Water Act, Federal Coastal Zone Management Act y normas estatales ad hoc ${ }^{64}$ ). Ciertamente, la coordinación y la participación son necesidades e instrumentos poderosos en la resolución de los problemas ambientales.

\section{LA JURISPRUDENCIA DE LA SUPREM COURT 65}

El conflicto medio ambiente $v$. desarrollo ha sido resuelto de forma diversa y no uniforme en la jurisprudencia de la Suprem Court. Junto a decisiones marcadamente ambientalistas es posible encontrar expresiones poco o nada sensibles a los valores ambientales. Como botones de muestra hemos escogido los siguientes pronunciamientos: Union Electric Co. v. Environmental Protection Agency; Tennessee Valley Authority v.

64 LrvaudaIS, "Conflict interest in Southern Louisiana's Wetlands...», cit., págs. 1.033, 1.017 y 1.034 , respectivamente.

65 Esta jurisprudencia ha sido recopilada utilizando las bases de datos informatizadas LExIs y WestLaw. 
MEDIO AMBIENTE VERSUS DESARROLLO: EXPERIENCLAS EN EL DERECHO AMBIENTAL NORTEAMERICANO

Hill; United States v. State of New Mexico; Andrus v. Sierra Club; Citizens to Preserve Overton Park v. Volpe; Weimberger v. Catholic Action of Hawaii; California Coast Commission v. Granite Rock Company; Metropolitan Edison Company v. People Against Nuclear Energy; Flint Ridge Development Company v. Scenic River Association of Oklahoma; Amoco Production Company v. Village of Gambel; Robertson v. Methow; Brendale v. Confederated Tribes y Lujan v. Defenders of Wildlife.

\section{A) Union Electric Co. v. Environmental Protection Agency y Ten- nessee Valley Authority v. Hill: El positivismo ambiental en la Corte Suprema de los Estados Unidos}

En plena vorágine de la que ha venido en llamarse «década ambiental» se produjeron pronunciamientos pro ambiente de gran racionalidad expresión de un cierto sentido histórico. Así, en los inicios de la década de los setenta se produjeron pronunciamientos como Citizens to Preserve Overton Park v. Volpe 66, en el cual la Corte Suprema realizó una lectura expansiva de una norma ambiental 67. El Secretario de Transportes estaba autorizado para asignar fondos federales para la construcción de autopistas a través de tierras públicas dentro de un Parque Nacional siempre "que no existiera otra posible o prudente alternativa». La Corte Suprema rechazó la argumentación del Secretario, que mantenía que la Ley le confería un amplio margen de discrecionalidad, afirmando que no se ajustaba a la ley «una alternativa más destructiva y cara".

Del desconocimiento de los valores ambientales se marchaba con pasos ilusionados hacia el reconocimiento. Donde las leyes ambientales marcaban una supremacía valorativa de lo ambiental, la Corte Suprema afirmó esta prioridad axiológica. En este sentido, Union Electric Co. v. Environmental Protection Agency 68 constituye un paso importante hacia la conciencia ambiental no meramente retórica. El supuesto de hecho de esta Sentencia dictada el 25 de junio de 1976, ponente el juez MarsHALL, fue el siguiente: Una empresa dedicada a la producción eléctrica, propietaria de tres Centrales Térmicas, que prestaba sus servicios al

66401 U. S. 402 (1971).

67 Goldsmith \& BANKs, «Environmental values: Institutional responsability...», cit., pág. 33.

68427 U. S. 246; 96 S Ct. 2.518 (1976) 
área metropolitana de St. Louis, Missouri, y parte de Iowa e Illinois, decidió recurrir la aprobación del Administrador de la E.P.A. de un plan del Estado de Missouri que establecía estándares de emisión de dióxido de sulfuro. La empresa básicamente alegaba que los niveles fijados eran impracticables desde el punto de vista económico y tecnológico. La Corte Suprema declaró que el lenguaje legal utilizado en la Clean Air Act en la sección 110 (a)(2) no permitía otra opción. Este precepto ordenaba aprobar los planes estatales implementadores al Administrador si cumplían ocho criterios expresamente formulados -concretamente se empleaba la expresión el Administrador "deberá aprobar» (shall aprove). Es lo que podemos denominar una posición positivista ambiental, lejos del posibilismo ambiental. El lenguaje utilizado, según la Corte Suprema, dejaba «bastante claro, que al Administrador no le vinculan otros factores que aquéllos expresamente establecidos, y en ninguno de los criterios especificados parece permitirse la consideración de la impracticabilidad tecnológica o económica" 69. Aunque la Clean Air Act y sus diferentes enmiendas permiten la toma en consideración de reclamaciones basadas en la impracticabilidad tecnológica o económica, el límite infranqueable para dichas demandas es la imposibilidad de interferencia sustancial del objetivo básico que constituye el logro del estándar nacional de calidad del aire ${ }^{70}$. En el voto particular, formulado por el Juez Powell, se dejaba traslucir una amplia oposición a los planteamientos mayoritarios de la Corte. En su opinión, el cierre de la Central eléctrica,

«podría tener incluso un mayor impacto sobre la salud de los ciudadanos que el creado por la degradación de la calidad del medio ambiente atmosférico. El resultado aparente requerido por esta legislación en su actual interpretación podría sacrificar el bienestar de una gran área metropolitana a través de la imposición de inflexibles demandas que pueden ser tecnológicamente imposibles e incluso no necesarias para el logro del objetivo de la pureza del aire. Creo que si el Congreso hubiese estado advertido de esta draconiana posibilidad hubiera realizado un balance distinto" 71 .

Quizá el pronunciamiento más relevante de los que vamos a examinar sea Tennesee Valley Authority v. Hill 72, Sentencia dictada el 15 de

696 S. Ct. at 2.525 .

70 At. 2.531 .

${ }^{71}$ At. 2.532. 
junio de 1978 en la que fue Ponente el Juez Burger. Diversos grupos ambientalistas ejercitaron acciones bajo la Endangered Species Act de 1973 para obligar a la Tennessee Valley Authority a desistir de la finalización de las obras de una presa y el cierre del río Little Tennessee. La Corte de Distrito rechazó dicha pretensión ${ }^{73}$. Apelada, esta decisión fue dejada sin efecto por la Corte Federal de Apelación ${ }^{74}$. La Corte Suprema confirmó esta última decisión. El problema de fondo era el siguiente: En 1973, cuando una presa estaba construida al 50\% (la Tellico Dam project) una especie de pez, denominada popularmente snail darter 75 , fue descubierta en un tramo del río afectado por la presa.

En 1975, cuando la presa estaba construida al $75 \%$ el Secretario del Interior incluyó a la snail darter en la lista de especies amenazadas. El Secretario del Interior, con fundamento en la sección 7 de Endangered Species Act ${ }^{76}$, promulgó un Reglamento ordenando a todas las Agencias federales adoptar las medidas adecuadas para asegurar que las actuaciones autorizadas, financiadas o llevadas a cabo por ellas no provocaran la destrucción o alteración de dicha zona de hábitat crítico. La Corte Suprema confirmó el fallo de la Corte Federal de Apelación. En su opinión, los antecedentes legislativos del precepto en su tramitación parlamentaria revelaban «una decisión explícita del Congreso de ordenar a la Administración que ésta otorgase prioridad a «la política nacional de preservación de las especies amenazadas", así como "la decisión consciente de dar a las especies amenazadas prioridad sobre las inmediatas misiones de las Agencias administrativas». Para la Corte Suprema "la clara intención del Congreso al promulgar dicha Ley fue detener e invertir la tendencia hacia la extinción de las especies, al costo que fuese» 77.

72437 US 153; 98 S. Ct. 2.279 (1978).

73419 F. Supp. 753 (US District Court for the Eastern District of Tennessee).

74549 F. 2d. 10.641.

75 Literalmente «caracol corredor".

76 «Cada Agencia Federal deberá, en consulta y con la asistencia del Secretario del Interior, asegurarse de que ninguna acción autorizada, financiada o llevada a cabo por tal Agencia... sea susceptible de poner en peligro la continuidad de la existencia de cualquier especie en peligro o amenazada, modificar o destruir adversamente el hábitat de tales especies que sea determinado por el Secretario, después de la consulta, si es apropiado con los Estados afectados, como "hábitat crítico", a menos que haya recibido una dispensa del Comité previsto en subsección (h) de esta sección En el cumplimiento de los requisitos de este precepto cada Agencia deberá usar los mejores datos científicos y comerciales disponibles».

$7798 \mathrm{~S}$. Ct. at 2.297. La Corte Suprema deducía la prioridad del lenguaje empleado por la Endangered Species Act a lo largo de su texto. Así, la Corte Suprema aludía al empleo de 
El fallo es sumamente interesante porque resuelve el conflicto medio ambiente-desarrollo de forma contraria a la solución adoptada por nuestro Tribunal Constitucional. Al plantearse el conflicto la Suprem Court afirmó lo siguiente, siendo consciente de que su decisión tenía un alto coste económico cifrado en millones de dólares que podrían sobrepasar el "precio" del snail darter:

"Ni la Endangered Species Act ni el art. III de la Constitución asigna a las Cortes Federales autoridad para realizar cálculos utilitaristas de tal clase. Por el contrario, el claro lenguaje de la Ley amparado por sus antecedentes en la redacción, muestra de manera diáfana que el Congreso consideraba el valor de las especies en peligro como incalculable» 78 .

El lenguaje utilizado por el Congreso, en la opinión de la Corte Suprema, dejaba suficientemente claro que «ese balance entre los valores en conflicto ha sido realizado en favor de las especies en peligro, asignándole la más alta prioridad, adoptando una política que es calificada como "protección institucionalizada» (institutionalized caution). Así las cosas, en virtud del principio de separación de poderes no podía el Alto Tribunal hacer decaer la ley mediante una decisión judicial acorde con el sentido común o la idea del bienestar público ${ }^{79}$. En contra del pronunciamiento fue formulado un voto particular por el Juez PoWELL, coincidiendo con éste el Juez BLACKMUN. Los ejes de dicho voto particular se centraban en dos argumentos. La irretroactividad de la Endangered Species Act., esto es, no era aplicable a un proyecto anterior (Tellico Dam comenzó a ejecutarse en 1966) ${ }^{80}$. Y la permanente sombra autorizadora del Congreso sobre dicho proyecto (por ejemplo, asignando fondos) ${ }^{81}$. El voto particular expresó su oposición a una Sentencia «más que por su alcance sobre una población de un área económicamente deprimida, por la continua amenaza sobre cualquier actuación de todos los proyectos federales, sin tener en cuenta su importancia para la Nación» 82.

frases como «Todos los Departamentos Federales deberán tratar de conservar las especies amenazadas y en peligron; la posibilidad de todo ciudadano de pedir la inclusión de una determinada especie en Catálogos, etc.

$7898 \mathrm{~S}$. Ct. at 2.298.

$7998 \mathrm{~S}$. Ct. at 3.302.

$8098 \mathrm{~S}$. Ct. at 2.305 et 2.307 .

$8198 \mathrm{~S}$. Ct. at 2.304.

82 Idem at 2.310. Desgraciadamente un posterior cambio legislativo dejó sin efecto la sentencia, construyéndose la presa. Afortunadamente, al final el snail darter era más común de lo que pareció en principio y fue hallado en otros ríos: doble lección. 
MEDIO AMBIENTE VERSUS DESARROLLO: EXPERIENCLAS EN EL DERECHO AMBIENTAL NORTEAMERICANO

De signo distinto, pero en la misma línea de positivismo ambiental (sólo existe primacía en la medida en que ésta haya sido establecida por las leyes) ha de citarse el pronunciamiento Amoco Production Company v. Village of Gambel 83. En esta Sentencia, dictada el 24 de marzo de 1987, se enjuiciaba una controversia referida a la explotación petrolífera en la plataforma continental de Alaska. La sección 810 a) de la Alaska National Interest Land Conservation Act determina que las Agencias federales, antes de permitir o autorizar el uso, ocupación o disposición de tierras públicas que pudieran restringir significativamente el uso de dichas tierras por los nativos de Alaska para su subsistencia, deberán realizar una información pública a fin de determinar que la posible restricción de uso es necesaria y fijar las medidas razonables para minimizar su impacto. Dos ciudades de Nativos de Alaska y una Organización Nativa acudieron a la Corte de Distrito solicitando una injunction 84 que prohibiera las explotaciones de petróleo y gas concedidas por el Secretario del Interior a la Amoco Production Company. Frente al pronunciamiento de la Corte de Distrito, la Corte Federal de Apelación del Noveno Circuito entendió aplicable las previsiones de la Alaska National Interest Land Conservation Act a la plataforma continental 85. La Corte Suprema revocó esta decisión. Para la Corte Suprema los antecedentes legislativos de la Alaska National Interest Land Conservation Act impedían considerar a la misma aplicable a la plataforma continental ${ }^{86}$, y el propósito de la citada sección 810 a) es "proteger los recursos de una innecesaria destrucción, y no prohibir todo uso de las tierras federales que pudiera afectar adversamente tales recursos» 87 . Lo importante a los efectos de nuestro estudio es la visión de la Suprem Court sobre la Ley citada. La Corte Federal de Apelación consideró que la Alaska National Interest Land Conservation Act situaba los objetivos de preservación sobre cualquier otro. Para la Corte Suprema dicha Ley declaraba la preservación como un interés público que debería ser reconciliado

83107 U. Ct. 1.396 (1987).

84 Una injunction es «una orden de un Tribunal dirigida a que una persona se abstenga de hacer o continúe haciendo, o continúe omitiendo una determinada acción que es objeto de reclamación" (Curzon, Dictionary of Law, third edition, Pitman London, 1991, pág. 224).

85746 F. 2d. 572 (1984).

86107 S. Ct. at 1.405.

87 fdem at 1.403 . 
con otros en conflicto hasta donde fuese posible. Literalmente la Corte Suprema afirmó:

«El Congreso no estableció de forma clara en la Alaska National Interest Land Conservation Act que los usos de subsistencia de los nativos son siempre más importantes que el desarrollo de recursos energéticos u otros usos de las tierras federales. Por el contrario, ésta expresamente declara que la preservación es un interés público y establece el marco para la reconciliación hasta donde sea posible de los intereses en conflicto» 88 .

No todos los pronunciamientos de la Corte Suprema han sido pro ambiente. Incluso en la denominada década ambiental existen garbanzos negros. En United States $v$. State of New Mexico ${ }^{89}$, Sentencia dictada el 3 de julio de 1978, Ponente Juez REHNQUIST, se decidió sobre la asignación de un recurso escaso —el agua-. Los Estados Unidos impugnaron la adjudicación de aguas realizada por el Estado de Nuevo México en 1970, a fin de determinar la cantidad exacta de agua correspondiente a cada usuario del caudal del río Mimbres. El Gobierno federal alegaba la existencia de derechos reservados de aguas para la preservación ambiental del Gila National Forest. La Corte Suprema rechazó tal pretensión afirmando que los derechos reservados sólo alcanzaban los necesarios para la explotación maderera, negando la reserva de uso para la protección de la fauna salvaje y usos recreacionales y estéticos. El fundamento de tal limitación lo encontraba la Corte Suprema en los motivos que impulsaron a la creación del National Forest System (Organic Administration Act de 1897, etc.) ${ }^{90}$. Frente a esta posición el Juez POWELl formuló voto particular, coincidiendo con éste los Jueces BRENNAN, White y MaRshall. En su opinión los Montes o Bosques Nacionales son un todo inseparable que reúne elementos inanimados y animados (pájaros, animales, peces, vida salvaje que habitan en ellos como lo hacen los árboles, las flores o la hierba). Por eso, de los limitados propósitos que impulsaron la creación de los National Forest no se deriva

$88 \mathrm{fdem}$ at 1.404. Un fallo de la Corte Suprema en buena medida en la misma línea es Secretary of the Interior $v$. California $(104 \mathrm{~S}$. Ct. 656, 1984). En él se rechazó que la concesión de explotaciones de petróleo o gas fuera una actividad que afectase directamente la zona costera a los efectos del artículo 307 (c)(1) de la Coastal Zone Management Act, que exige la adecuación de tales actividades a los planes y programas de gestión aprobados por los diferentes Estados.

89438 U. S. $699 ; 98$ S. Ct. 3.012 (1978).

9098 S. Ct. at 3.020 . 
«que el Congreso no considerara la vida salvaje como parte de los Forest que sería deseable promocionar y proteger para las futuras generaciones» 91 . En definitiva, frente a la posición más ambientalista del voto particular, la Corte Suprema realizó una lectura positivista apegada a la letra de la Ley, aunque muy probablemente separada de su espíritu.

Más reciente en el tiempo es Manuel Luján, $J r$, Secretary of the Interior, Petitioner V. Defenders of Wildlife et al., Sentencia dictada el 12 de junio de 1992 (siendo ponente el Juez SCALIA, y formulando voto particular el Juez BLACKMUN). En este caso se enjuiciaba la impugnación de un reglamento promulgado por el Secretario del Interior interpretando la sección séptima, apartado (a)(2) §7 de la Endangered Species Act de 1973 (16 U.S.C. § 1536), a los efectos de dilucidar si dicha ley era aplicable sólo a actuaciones dentro de los Estados Unidos y en altamar o si también lo es a actuaciones en otros países (fuera de los Estados Unidos) ${ }^{92}$. La negación de legitimación fue la argucia usada para la ablación de la defensa de los valores ambientales. La decisión de la Corte Suprema fue considerar que los ahora demandados carecían de standing para entablar la acción, revocando la decisión precedente de la Corte Federal de Apelación.

Tras delimitar los elementos del test de standing 93 la Suprem Court consideró que la Sentencia precedente de la Court of Appeals había sido una resolución errónea al denegar la moción del Secretario para el juicio sumario, ya que "los demandados no habían cumplido el requisito de la demostración del perjuicio y de su reparabilidad» 94 .

\footnotetext{
$918 \mathrm{~S} . \mathrm{Ct}$. at $3.021-3.022$
}

$92 \mathrm{El}$ fondo de la controversia se refería a proyectos de desarrollo financiados por Agencias de la Administración norteamericana. Los grupos pro defensa de la vida salvaje habían presentado informes acerca de las repercusiones sobre el hábitat del cocodrilo del Nilo de acciones destinadas a la rehabilitación de la presa de Assuán en desarrollo del Master Plan de Agua en Egipto. Otro informe fue acerca de las repercusiones sobre el elefante asiático y el leopardo, afectados por el "proyecto Mahaweli», financiado por la Agencia para el Desarrollo Internacional, Sri Lanka.

93 Recuérdese que éstos son: 1) La parte debe haber sufrido un Injury in fact, un perjuicio real, entendido "una invasión de un interés legalmente protegido el cual es concreto y particularizadon y actual o inminente, no hipotético o conjetural; 2) debe existir un nexo causal entre el perjuicio y la conducta impugnada, "el perjuicio ha de ser claramente deducible de la actuación impugnada y no el resultado de una actuación independiente de un tercero no presente ante el Tribunaln; 3) debe ser probable en oposición a meramente especulativo, el perjuicio será susceptible reparado por una decisión favorable.

94 El segundo eje de la Sentencia fue la falta de demostración de reparabilidad del perjuicio. Los demandados habían escogido impugnar la norma reglamentaria, en vez de 


\section{B) Administración competente para la determinación del interés prevalente en conflicto: California Coast Commission v. Granite Rock Company. El poder regulador de los pueblos indígenas}

A veces la expresión del conflicto medio ambiente-desarrollo ha planteado la importante cuestión de cuál es la instancia adecuada de decisión en el nivel normativo o ejecutivo. La Corte Suprema ha admitido la participación de los Estados en la determinación del interés prevalente en conflicto. En California Coast Commission v. Granite Rock Company 95, Sentencia dictada el 24 de marzo de 1987, la Corte Suprema decidió sobre la legalidad de la exigencia de California Coast Commission de una autorización adicional en relación con la actividad minera desarrollada por la Granite Rock Company en tierras federales (National Forest). La Mining Act de 1872 autoriza a los particulares a entrar en las tierras federales para realizar actividades de exploración minera, denunciar explotaciones y obtener "patentes (el equivalente a nuestras concesiones). La Granite Rock Company había obtenido en 1981 la aprobación de una Agencia federal, el Forest Service, de un plan quinquenal de explotación de roca caliza. En 1983 la California Coast Commission ejecutando un mandato contenido en una Ley estatal (la California Coastal Act) se dirigió a la citada compañía requiriéndole a fin de que solicitase autorización respecto de las actividades mineras ejercidas. La Corte Federal de Apelación había estimado los argumentos de la compañía minera y declaró que «el establecimiento de un sistema de autorizaciones independientes para hacer cumplir estándares ambientales estatales podría socavar la autoridad autorizante del Forest

impugnar las acciones específicas en ejecución de dicha norma. En la opinión de la Suprem Court, el problema más obvio en el presente caso era la "reparabilidad":

"Ya que las Agencias que financian proyectos no fueron partes en el proceso, la Corte de Distrito podía acordar sólo medidas contra el Secretario. Este podría ser obligado a revisar su regulación a fin de requerir la consulta para los proyectos en el extranjero. Pero ello no constituiría una medida de reparación frente al perjuicio alegado, a menos que las Agencias financiantes fueran requeridas por la regulación del Secretario, lo cual es una cuestión bastante discutible e indefinida... Los demandados afirman que esa indefinición legal no afecta a la reparabilidad porque la Corte de Distrito podía por sí misma resolver la cuestión de la autoridad del Secretario como una parte necesaria de su indagación acerca del standing. Asumiendo que sea correcto resolver una cuestión de Derecho como ésa en conexión con los límites de la indagación acerca del standing, la resolución de la Corte del Distrito no habría reparado el perjuicio alegado de ninguna forma, porque no habría sido obligatoria para las Agencias. Ellas no fueron partes en el proceso y no hay ninguna razón por la cual ellas debieran ser obligadas a reconocer la incidental determinación legal que el proceso produjo".

95107 S. Ct. 1.149 (1987). 
MEDIO AMBIENTE VERSUS DESARROLLO: EXPERIENCIAS EN EL DERECHO AMBIENTAL NORTEAMERICANO

Service» 96. La Corte Suprema rechazó la pretensión de la Compañía minera que postulaba la inexigibilidad de la autorización de la California Coast Commission, por entender que ésta no estaba excluida por las leyes federales. La compañía mantenía que la ley estatal en virtud de la cual era exigida la autorización constituía una regulación urbanística del uso de las tierras federales y que, en tanto tal, estaba constitucionalmente excluida. La Corte Suprema estimó que la exigencia de autorización constituía «un ejercicio de regulación ambiental antes que ordenación del territorio" (land use planning). Los Jueces Powell y STEvens formularon voto particular. A los efectos de nuestro estudio es de resaltar una de las motivaciones de su disidencia. En su opinión, el problema de hecho radicaba en que la Corte Suprema había otorgado a la California Coast Commission el poder de prohibir a la Granite Rock Company el ejercicio de derechos otorgados por una autorización del Forest Service. Ello «constituía una abdicación del control federal sobre el uso de las tierras federales sin precedentes" 97. Desde el punto de vista de los Jueces disidentes, el peligro de un doble permiso era evidente: «El sistema de autorizaciones federales refleja un cuidadoso balance entre dos importantes intereses federales. El interés en el desarrollo de los recursos minerales en tierras federales, y el interés en la protección de los National Forest de daños ambientales». Por tanto, en su opinión, permitir a la California Coast Commission realizar un balance distinto necesariamente pugnaba con el sistema federal.

En Brendale v. Confederated Tribes ${ }^{98}$, se decidió sobre un conflicto medio ambiente-desarrollo en una Reserva India. Los demandantes poseían terrenos en el seno de una reserva y solicitaron permisos del Departamento de Planeamiento del Condado de Yakima. Dichas solicitudes eran acordes con las zoning ordinances del Condado, pero contrarias a las zoning ordinances de la Tribu. En esta Sentencia de 29 de junio de 1989, la Corte Suprema afirmó la autoridad de las Tribus Indias para restringir el uso de los derechos de propiedad pertenecientes a individuos que no sean miembros de la tribu, a través de las zoning ordinances en aquellas áreas de la Reserva cerradas a la población general. Esta restricción de uso pueden alcanzar a individuos que no sean miembros de la tribu que proyecten el establecimiento de áreas residenciales que

96768 F. 2d. 1.077.

$97107 \mathrm{~S}$. Ct. at 1.437.

98109 S. Ct. 2.994 (1989). 
puedan amenazar los valores espirituales y culturales de un área única y virgen ${ }^{99}$.

\section{C) La judicialización de los conflictos desde la National Environ- mental Policy Act}

Los conflictos planteados por proyectos de desarrollo en áreas sensibles han sido judicializados de la mano de la N.E.P.A., y en concreto, desde la técnica de la Evaluación de Impacto Ambiental. La Corte Suprema ha venido a devaluar las interpretaciones expansivas y garantistas de los Tribunales inferiores.

Así, en Andrus v. Sierra Club 100 , Sentencia dictada el 11 de junio de 1979, Ponente el Juez Brennan, se enjuiciaba si una propuesta de presupuesto a cargo del Fish and Wildlife Service, del Departamento del Interior, o la O.M.B. (Oficina de Administración y Presupuesto) que suponía un recorte de los fondos asignados al National Wildlife Refuge System constituía una Federal Major Action o una proposal for legislation sujeta a la N.E.P.A., siendo por tanto necesaria la realización de un estudio de impacto ambiental. La Corte Suprema, frente a la posición de la Corte de Distrito y de la Corte Federal de Apelación, estimó que la N.E.P.A. era inaplicable a una mera propuesta de presupuesto. La necesidad de Evaluación de Impacto Ambiental es «aplicable a aquellas recomendaciones o informes que realmente proponen acciones programáticas y no a aquéllas que meramente sugieren cómo deberían ser financiadas las actuaciones» 101. En Metropolitan Edison Company v. People Against Nuclear Energy 102, la Corte Suprema decidió sobre un asunto relativo a la energía nuclear. People Against Nuclear Energy (Ciudadanos en contra de la Energía Nuclear, en adelante P.A.N.E.), una asociación de residentes del área de Harrisburg respondieron a la invitación de la Nuclear Regulatory Commision (en adelante N.R.C.), para participar en una información pública. Uno de los reactores nucleares de la Central de Harrisburg había sufrido un accidente grave. La N.R.C. ordenó la parada inmediata del reactor T.M.I.-1, que se hallaba desco-

99 At 2.998.

10099 S. Ct. 2.335 (1979).

10199 S. Ct. at 4.332.

102460 U. S. 763; 103 S. Ct. 1.556 (1983). 
nectado para la recarga de combustible, a fin de determinar si podría continuar en funcionamiento en condiciones de seguridad. P.A.N.E. alegó que la vuelta al funcionamiento del reactor les ocasionaría daños psicológicos. Estas alegaciones no fueron tomadas en cuenta. La Corte Suprema declaró en esta Sentencia que la Evaluación de Impacto Ambiental era sólo exigible respecto de actuaciones que tuvieran impacto sobre el ambiente físico 103 y que la N.E.P.A. no era de aplicación dada la ausencia de conexión directa del daño alegado respecto del ambiente físico, así como la imposibilidad de aplicación respecto de actuaciones administrativas del pasado ${ }^{104}$. Más interesante a los efectos de nuestra investigación es la posición de la Corte Suprema frente a la alegación de P.A.N.E., según la cual el daño a su salud psicológica se derivaba directamente del riesgo de accidente nuclear. La Corte Suprema adoptó una posición ciertamente posibilista: en su opinión «El riesgo es un elemento omnipresente de la vida moderna, la mayoría de los riesgos a los que nos enfrentamos son generados por la moderna tecnología, lo cual trae como resultado la posibilidad de grandes accidentes y la oportunidad de enormes conquistas". Si a la energía nuclear se une la razón militar, esa suma tiene como resultado Weimberger v. Catholic Action of Hawaii 105, Sentencia dictada el 1 de diciembre de 1981, de la cual fue Ponente el Juez Rehnouist. En esta Sentencia la Corte Suprema decidió sobre la necesidad de Evaluación de Impacto Ambiental. La United States Navy (la Armada) había determinado almacenar armas nucleares en una base de Hawai. La Corte de Distrito rechazó tal petición realizada por la asociación Catholic Action of Hawaii y el Peace Education Proyect 106. La Corte Federal de Apelación revocó esta decisión declarando la necesidad de realizar una hipotética Evaluación de Impacto Ambiental (hipotetical E.I.S.) de acuerdo con las prescripciones de la N.E.P.A. ${ }^{107}$. La Corte Suprema en la Sentencia antes citada declaró que no podía ser exigida la preparación de un documento no previsto (al ser "hipotético» 108) y que las previsiones de la N.E.P.A. eran inaplica-

103103 S. Ct. at $1.560-1.561$.

104103 S. Ct. at 1.563.

105102 S. Ct. 197 (454 U. S. 139, 1981).

106468 F. Supp. 190 (U. S. District Court for District of Hawaii).

107643 F. 2d. 659 (9th Circuit, 1980).

108 Según la Corte Suprema sólo podía ser objeto de evaluación la instalación efectiva de armas nucleares, pero no la construcción de instalaciones capaces de albergarlas. La ins- 
bles en virtud de las disposiciones legales sobre secretos oficiales (Freedom of Information Act). A pesar de la negativa a la publicidad implícita de la Evaluación de Impacto Ambiental, la Corte Suprema declaró que la Armada tenía el deber de tomar en consideración las consecuencias sobre el medio ambiente en su proceso decisional, incluso si no pudiera cumplir con los objetivos de publicidad de la N.E.P.A. en virtud de la primera de las excepciones derivadas de la Freedom of Information Act (el secreto militar) ${ }^{109}$.

En Flint Ridge Development Company v. Scenic River Association of Oklahoma 110 la Corte Suprema rechazó la exigencia de Evaluación de Impacto Ambiental respecto de una decisión del Department of Housing and Urban Environment, que denegó la solicitud realizada en tal sentido por la Scenic River Association of Oklahoma. Esta Asociación mantenía que la aprobación y registro por dicho Departamento de un informe necesario en virtud de la Interstates Land Sales Full Disclosures Act constituía una Federal Major Action y que, por tanto, estaba sujeta a la N.E.P.A y era necesaria la realización de un estudio de impacto ambiental. La Corte Suprema rechazó tal argumentación en virtud de los estándares de protección ya establecidos por la Interstates Land Sales Full Disclosures Act.

En Robertson v. Methow 111, la Suprem Court revocó una decisión de la Federal Court of Appeal for the Ninth Circuit 112. Se trataba de enjuiciar una autorización concedida por el Forest Service para destinar parte de un National Forest para usos recreacionales, en concreto, una estación de esquí. Cuatro organizaciones ciudadanas impugnaron el permiso concedido y, entre ellas, la Methow Valley Citizens Council. Frente a la posición de la Corte Federal de Apelación, la Corte Suprema afirmó que la N.E.P.A. no impone un deber sustantivo sobre las Administraciones a fin de evitar efectos ambientales adversos (el deber es de natu-

talación efectiva no podía ser revelada al público en ningún caso en virtud de la legislación de secretos oficiales. Por eso, la evaluación que declaró la Corte Federal de Apelación era hipotética, esto es, en la media en que en un futuro se albergasen. Pero la evaluación hipotética, un EIS hipotético, no estaba legalmente previsto en la NEPA, según la Corte Suprema (vid. 192 Ct. at 202-203).

109 fdem at 203.

11096 S. Ct. 2.430 (426 U. S. 776,1976$)$.

11157 U. S. L. W. 4.497 (1989).

112833 F. 2 d. 810. 
raleza procesal, «N.E.P.A. itself does not mandate particular results, but simply prescribes the necessary process) ni la obligación de incluir en cada environmental impact statement (estudio de impacto ambiental) un plan detallado de medidas correctoras (a complete mitigation plan).

\section{CONCLUSIONES}

Del examen realizado del Derecho americano pueden extraerse diversas líneas maestras a seguir, sin necesidad de escarmentar en cabeza propia. Las normas ambientales que establezcan prioridades entre los intereses en conflicto - por supuesto, dentro del marco constitucionalmente posible- deben imponer estándares materiales y no sólo procesales. Ejemplos en la jurisprudencia de la Suprem Court avalan esta necesidad (así, Amoco Production Company v. Village of Gambel o Strycker's Bay Neightborhood Council v. Karlem). Si las leyes no precisan su alcance, lo más normal es que sean interpretadas restrictivamente en contra de los valores de preservación. Las previsiones de prevalencia racionales, proporcionales y equilibradas deben descansar sobre claros mandatos no sólo procedimentales. La otra cara de la moneda de este positivismo ambiental es la clarificación de lo que podríamos denominar parámetros de implantación efectiva. Las normas ambientales han de establecer una gradación material de prioridades de forma expresa y diáfana. Esa es la forma de vincular a la Administración y a los órganos jurisdiccionales. Los valores ambientales han sido respetados en la jurisprudencia americana cuando el lenguaje del legislador no dejaba otra alternativa. (Unión Electric Co. v. Environmental Protection Agency). Pero, ¿cómo fijar esas prioridades? Nadie tiene la respuesta a esta pregunta clave en nuestra generación. El caso concreto no puede decidirse con una regla precisa por la elemental razón de la imposibilidad de normación expresa de un billón de supuestos de hecho. Sólo es posible ofrecer reglas generales y usar conceptos jurídicos indeterminados de amplio halo. El desarrollo sostenible es el concepto integrador capaz de solucionar el dilema. El signo de los tiempos requiere un Derecho asumido antes que impuesto. En este sentido, Snail Darter no es un ejemplo de preservación inteligente 113 . Dudo

113 No siendo un experto en ciencias ambientales experimentales, albergo la sospecha de que frente a la solución adoptada en Tennessee Valley Authority v. HiLL existían otras alternativas. La diversidad biologica, ciertamente constituye un elemento irrenunciable del derecho a un medio ambiente adecuado. ¿Pero no hubiera sido posible la conservación de esta especie en otro hábitat similar previa adaptación al mismo? Templos egipcios fueron transportados piedra a piedra para la construcción de la presa de Assuán. ¿No hubiera sido posi- 
seriamente que lo absoluto sea a la larga más efectivo que lo gradual. En este marco que se propone, sin embargo, no debe descartarse la imposición de primacías absolutas. Eso probablemente sea otro de los signos de nuestra era. La posibilidad de establecimiento de la primacía de lo ambiental en determinados supuestos. La admisión de primacía no puede, sin embargo, convertirse en regla general. La primacía ha de basarse en razones científicas y culturales. Esta no puede estar sometida a estimaciones más o menos coyunturales, o en el peor de los casos, a la decisión arbitraria y caprichosa de un tecnócrata. El ambiente no puede ser introducido en un frasco de formol o en un congelador. La Administración Ambiental no debe imitarse a un puro taxidermismo.

El reto fundamental de las normas ambientales es hacer confluir los intereses en conflicto. En ese desafío no puede haber frustración sino solidaridad. Ni frustración de objetivos (ya preservacionistas/ya desarrollistas), ni frustración de colectivos. Es evidente que el principio afirmado tiene su aplicación directa en materia ambiental. No quiere decirse con ello que de la mano de la acción pública no voluntarista se hayan de enriquecer privilegiados. Las limitaciones al desarrollo sí deben ser indemnizables. ¿Con qué legitimidad moral podemos pedir a los países del tercer mundo que conserven zonas o recursos esenciales para nuestra supervivencia (como la Amazonia, los bosques tropicales, las reservas naturales...)? ¿Dónde reside dicha legitimidad para la imposición de restricciones al desarrollo a las poblaciones en espacios naturales protegidos o en zonas de influencia? ¿Cómo pueden exigir los países del norte de Europa con rentas per capita y tasas de población activa muy superiores que el $30 \%$ de la provincia de Huelva sea espacio protegido?

Dada nuestra nula intención de pagar por lo que consideramos erróneamente que nada vale, no queda otra alternativa que asignar valor económico a la preservación. La primera acción necesaria es, como ha defendido PÉREZ MORENo, la conversión de las normas de acción en normas de relación ${ }^{114}$. Los conflictos no se solucionan mediante deseos

ble adaptar la construcción de la Telico Dam a la supervivencia de la especie? ¿O, es que el bien jurídico protegido subyacente fue la intangibilidad frente a un alternativo desarrollo sostenible compatible con el bien jurídico protegido - el ambiente- $\mathrm{y}$ a proteger)?

114 Esto implica «ir convirtiendo las normas de acción - aquéllas en las que entre el "Boletín Oficial" y el resultado no hay más que la voluntad del destinatario de la prohibición o el mandato-, en normas de relación, en las que las cargas se transforman en obligaciones exigibles por las partes» ("Reflexiones sobre la sustantividad del Derecho ambiental", $R A P$, n. ${ }^{\circ}$ 100-102, enero-diciembre, 1983, págs. 2.782-2.784). 
MEDIO AMBIENTE VERSUS DESARROLLO: EXPERIENCIAS EN EL DERECHO AMBIENTAL NORTEAMERICANO

expresados en normas. El esquema de la estrategia, incorporando las técnicas que hemos descrito podría ser el siguiente:

1) Identificación de los valores a proteger mediante un programa a imagen y semejanza del National Landmark. La protección debe ser integral y racional. La lucha no debe limitarse a los valores declarados pues fuera de éstos existen bienes ambientales dignos de conservación. La determinación de lo protegible debe basarse en conocimientos científicos. Como hemos apuntado, la primacía ha de fundarse en razones científicas y culturales.

2) Una vez declarado un espacio, la idea de solidaridad (art.45.2 CE) debe presidir la actuación de las Administraciones Públicas de forma que los costos y limitaciones sean compartidos y asumidos por la sociedad (y en ella están incluidos al menos los ciudadanos de la Unión Europea). La acción no debe ser meramente testimonial. Si no es alcanzado un umbral compensatorio, el fracaso de Daimiel está garantizado. Los destinatarios de estos programas han de ser las poblaciones y los propietarios. Para ello habrán de ponerse en marcha los siguientes mecanismos en aquellos supuestos en que existan limitaciones severas al desarrollo:

- Puesta en marcha de un programa de adquisiciones estratégicas. El programa deberá ser audaz e imaginativo: a) Adquiriendo "frenos» a la expansión; b) Adquiriendo servidumbres; c) Incorporando otros mecanismos de financiación como la participación directa de la ciudadanía (creando títulos honoríficos de un metro cuadrado, como en la reserva de la tortuga Mora).

- Ejecución de un programa de derechos transferibles de desarrollo a escala autonómica con designación de áreas de donación y áreas de desarrollo potencial.

- Y puesta en marcha de un programa de instrumentos económico-fiscales con finalidades incentivadoras y disuasoras unidos a convenios.

Como ha dicho SAGofF, «la calidad del medio ambiente - la pureza del aire y del agua, la integridad de los ecosistemas- funcionan como símbolos por los cuales seremos conocidos y juzgados" 115 . Si esto es así, no cabe la menor duda de que es nuestra obligación hacer todo lo necesario -incluyendo la asunción de los costos económicos.

115 "Where Ickes Went right or Reason and Rationallity...», cit., pág. 321. 


\section{Sección Jurisprudencia}

REALA-1994, núm. 264. JORDANO FRAGA, JESUS. MEDIO AMBIENTE VERSUS DESARROLLO: EX... 
REALA-1994, núm. 264. JORDANO FRAGA, JESUS. MEDIO AMBIENTE VERSUS DESARROLLO: EX...

REALA-1994, núm. 264. JORDANO FRAGA, JESUS. MEDIO AMBIENTE VERSUS DESARROLLO: EX... 